Chapman University

Chapman University Digital Commons

$5-2014$

\title{
Creating the Back Ward: The Triumph of Custodialism and the Uses of Therapeutic Failure in Nineteenth Century Idiot Asylums
}

Philip M. Ferguson

Chapman University, pferguson@chapman.edu

Follow this and additional works at: https://digitalcommons.chapman.edu/education_books

Part of the Disability and Equity in Education Commons, Inequality and Stratification Commons, Other Sociology Commons, Social History Commons, and the United States History Commons

\section{Recommended Citation}

Ferguson, P. M. (2014). Creating the back ward: The triumph of custodialism and the uses of therapeutic failure in 19th century idiot asylums. In Ben-Moshe, L., Carey, A., \& Chapman, C. (Eds.), Disability incarcerated: Imprisonment and disability in the United States and Canada (pp. 45-62). New York: Palgrave Macmillan.

This Book is brought to you for free and open access by the Attallah College of Educational Studies at Chapman University Digital Commons. It has been accepted for inclusion in Education Faculty Books and Book Chapters by an authorized administrator of Chapman University Digital Commons. For more information, please contact laughtin@chapman.edu. 


\title{
Creating the Back Ward: The Triumph of Custodialism and the Uses of Therapeutic Failure in Nineteenth Century Idiot Asylums
}

\author{
Philip M. Ferguson
}

\section{Introduction}

In December 1965, Burton Blatt, along with photographer Fred Kaplan, made a series of visits to a variety of large public institutions for people with intellectual disabilities. They made special efforts at each facility to visit the 'back wards' and document what they knew they would find. The photographic exposé (Blatt and Kaplan 1966/1974) of the abuse and neglect that had become standard "treatment" in these institutions helped stoke the fires of outrage and shame among both politicians and the public, leading to the large-scale movement of the people forced to live in these conditions back to the community. The population of these large, public institutions peaked in 1967 at about 230,000 individuals and has continued to decline to a current population just under 30,000 (Larson et al. 2013, 7).

Blatt and Kaplan undertook their efforts, in part, to document the conditions that had outraged then Senator Robert Kennedy when he had visited some of the institutions in New York a few months earlier. Blatt wanted to assure everyone that what the Senator had witnessed was the rule, not the exception, in the incarceration of people with intellectual disabilities in 1965. One did not have to know how the situation had devolved to such a state to recognize the horror of what had come to be.

It is true that a short visit to the back wards of an institution for the mentally retarded will not provide, even for the most astute observer, any clear notion of the antecedents of the problems observed, the complexities of dealing with them, or ways to correct them. We 
can believe that the Senator did not fully comprehend the subtleties, the tenuous relationships, the grossness of budgetary inequities, the long history of political machinations, the extraordinary difficulty in providing care for severely mentally retarded patients, the unavailability of highly trained leaders, and the near-impossibility in recruiting dedicated attendants and ward personnel. But, we know, as well as do thousands of others who have been associated with institutions for the mentally retarded, that what Senator Kennedy claimed to have seen he did see. In fact, we know personally of few institutions for the mentally retarded in the United States completely free of dirt and filth, odors, naked patients groveling in their own feces, children in locked cells, horribly crowded dormitories, and understaffed and wrongly staffed facilities. (Blatt $1974, v)$

It has been almost a half-century since Blatt’s observations of Christmas in Purgatory. Over the intervening years, we have become somewhat inured to the abuses of that earlier era. If conditions in the institutions that remain open are far from perfect, society seems to trust that the grossest of the conditions have been rectified. Yet people in North America remain familiar with the meaning of the term "back ward.” The "back wards"” are where the worst abuses happened. Both in fact and in symbol, the back wards of institutions were those out-of-sight hellholes where the inmates with the most significant disabilities, the most challenging behaviors, the most hopeless of prognoses were abandoned. If back wards still exist then surely they are the exception rather than the rule. At least that is the hope. However, whether actual back wards still exist or not, metaphorical "back wards” still surely do.

My focus in this chapter is on the origin of the back ward rather than its demise. Where did the "back wards" that Blatt and Kennedy witnessed come from in the first place? What 
exactly were those "antecedents of the problems observed" that Blatt cited? This chapter reviews that history and argues that, in fact, there is a specific narrative to the evolution of the institutional "back ward" as an identifiable place where people with the most significant intellectual disabilities were to be incarcerated and largely forgotten.

As a physical location, institutional back wards in North America were created in the last half of the nineteenth century. This is not to say that there was no abuse or neglect before that time. Of course there was. Indeed, it was the documentation of existing abuses in county poor houses that was the ostensible justification for the creation of new, state institutions built along a new architectural and administrative model that included separate "wards" or "cottages" located at the back of the institutional grounds. However, actual wards or units located at the back of institutional settings were arrangements that American institutions borrowed from European institutions as an administrative solution to a problem of managing an increasingly custodial population. The so-called cottage plan for institutions allowed the creation of ever larger, congregate facilities where separate, individual units were built to house specific types and levels of inmates, with the most custodial classifications assigned to those units the furthest away from the administration building.

Especially in New York State, the debate over the "cottage plan” was both contentious and extended. Exploring that debate and how it evolved from roughly 1860 to 1915 allows a more detailed understanding of the power of the back ward as both symbol and artifact of institutional incarceration of people with the most significant intellectual disabilities. It leads to a series of additional questions that are specific to New York, but suggestive of larger institutional models throughout North America. Why were the details of institutional provisions for those individuals judged to be hopelessly idiotic or at least unimprovably demented or imbecilic so 
persistently contested in New York State and elsewhere? An adequate response to that question must quickly move beyond the specific issues and personalities to a larger question about the uses and abuses of the concept of "therapeutic failure" in the professionalization of care for people with intellectual disabilities in the nineteenth and early twentieth centuries. ${ }^{2}$

The creation of the back ward, then, becomes the story of the move from care to custody to incarceration. After reviewing the key points of this story, I argue that the details of developmental classification and institutional organization underlying the debate over custodial care reveal the beginnings of a model of service (a so-called continuum of care) for people with intellectual disabilities that still dominates today despite the diminishing role of the residential institution.

\section{Locating Custody: The Debate over Separate or Congregate Care}

In December 1906, some 60 years before Blatt’s exposé, there were four state institutions in New

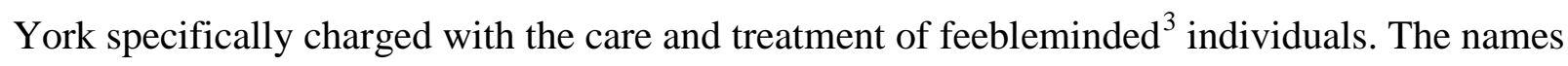
of the facilities were straightforward indications of their official purpose upon creation:

1. The Syracuse State School for Feeble-Minded Children (established 1852);

2. The State Custodial Asylum for Feeble-Minded Women (est. at Newark, 1878);

3. The Rome State Custodial Asylum (est. 1894);

4. The Craig Colony for Epileptics (est. at Sonyea, 1896)

The Syracuse facility — the second oldest public institution in the United States to focus specifically on the so-called feebleminded population-was the only one of the four to mention “school” and "children” in its name. This was suggestive of the facility’s official emphasis on the remediation — and even cure—of youth with mild or moderate intellectual disabilities, with a projected return of many of its residents to life in the community as productive, if supervised, 
young adults. The Rome and Newark facilities, by contrast, are identified as “asylums” not "schools," and the official function of incarceration in these asylums was "custodial" in nature rather than curative or even ameliorative. The Craig Colony ${ }^{4}$ facility clearly indicated its focus on individuals with epilepsy. For most institutional professionals of this era, epilepsy was, if anything, an even more dismal diagnosis than idiocy. Indeed, with some exceptions, epilepsy was often treated as a particularly hopeless category of feeblemindedness. According to one estimate, up to 98 percent of Craig's inmates were judged to be feebleminded (Hebberd 1912). In sum, two of the four "idiot asylums" in New York State at the dawn of the twentieth century were explicitly custodial in origin and purpose, and a third was implicitly custodial given the general view of incurability attributed to epilepsy.

It is, therefore, somewhat surprising to read in the Annual Report for the New York State Board of Charities how a special committee had set out in that same month of December 1906, to meet with the superintendents of the four asylums to discuss the very issue their institutions were designed to solve: what to do with the so-called custodial inmates that threatened to overwhelm the management of those custodial institutions? The summary of the meeting described the institution leaders as "greatly embarrassed" by the growing number of inmates "so demented as to be no longer capable of improvement, and to require, in the future, only custodial care” (New York State Board of Charities 1907, 24). The custodial asylums, in short, were seemingly ashamed that so many of their residents were, in fact, custodial. It had been at the behest of H. B. Wilbur, the first superintendent of the Syracuse State School, and others (especially Josephine Shaw Lowell ${ }^{5}$ ) that the Newark asylum had originally been established in 1878. Almost 20 years later, the creation of the institutions at Rome and Sonyea (Craig), New York, were likewise, in 
specific response to the complaint that the unimprovable inmates at Syracuse (and the county poorhouses) were crowding out the educational focus that was the prime mission of the facility.

If it was a familiar problem, the recommended solution coming out of the meeting also seemed strikingly repetitive, namely that the state should create another custodial asylum. However, the recommendation to create another asylum was not necessarily—or at least not primarily—to build the state's institutional capacity to handle larger and larger numbers of custodial inmates being admitted from the community. It was instead, to relieve the burden placed on the existing institutions by the custodial inmates already in residence.

After consideration of the various phases of the problem, the superintendents and managers present adopted unanimously a resolution recommending the establishment of a new custodial asylum, to which may be sent all inmates of the four existing institutions intended for epileptics and the feeble-minded, who are no longer proper subjects for treatment and maintenance therein. (New York State Board of Charities 1907, 24)

The question arises as to why the administrators of asylums that had already been established as custodial in nature (as was true of three of the four New York facilities) were so adamant in their insistence that a new custodial asylum was needed? There were certainly social concerns about the dangers of the umimprovable classes to the safety of morals of the general public. However, in this situation the superintendents were discussing where, not whether, to incarcerate individuals. The people in question were already in custody. There were also certainly concerns of economics and efficiency. Getting rid of those inmates who were physically or cognitively unable to contribute to their own care could be a significant cost savings. However, economic concerns alone do not explain why the superintendents would be "greatly embarrassed" by discovering that their institutions had precisely the individuals for whom their facilities had been 
intended. Instead, their apprehension seems at least partly grounded in a concern with professional legitimacy and therapeutic skill. Regardless of the original purpose of the custodial facilities, once in charge of such a place, the superintendents were just as vulnerable to the professional need to demonstrate special expertise and discernment in the treatment of their residents. One of the by-products of this demonstration was the ability to make classificational distinctions where none had been made before. So, just as the almshouse managers had in earlier eras felt it necessary to sort the economic failures into separate subgroups of able-bodied poor and truly dependent; just as the insane asylum superintendents insisted on distinguishing the curable insane from the chronic; so did the idiot asylum leaders find it important to distinguish the truly custodial from those who could be somewhat useful and amenable to improvement. ${ }^{6}$

Regardless of its origins or merits, the recommendation of the State Board of Charities to create a new custodial asylum was not immediately acted upon by the state legislature. It was not until some five years later (1911) that Letchworth Village was opened in downstate New York. More importantly, when opened, Letchworth was designated to receive individuals at all levels of functioning. It was to follow the pattern of congregate care adopted by virtually every other state and model itself as one of the all-purpose "villages of the simple" (Kerlin 1885, 174). Letchworth, in short, was both custodial and curative in official function. Despite the arguments of institution superintendents and State Board of Charities leaders, New York ended up following the rest of the country creating a network of idiot asylums across the state that were meant to "serve" all of those with any level of feeblemindedness. Asylums, in essence, were to create a continuum of care where separate cottages housed individuals with separate levels of support needs, while still connected organizationally under one administration. Instead of 
creating one or two institutions that were all "back wards," while others would supposedly have none, New York joined the other states in creating room for back wards at every institution.

\section{The Move to Congregate Care}

Interestingly, the last half of the nineteenth century was taken up with earlier versions of the same debate that the New York State Board of Charities was still considering in 1906. The earlier debates sometimes dealt with different sets of particular issues (e.g., economics, treatment regimens, prospects of cure or remediation, social welfare, ethical obligations). For a period of years, the arguments became bitter and personal. Yet they always revolved around a singular issue: what should be done with the growing number of individuals whose conditions remained impervious to professional help? Many of the details of this debate have already been ably recounted in histories of insane asylums (Dwyer 1987; Grob 1973; Schneider and Deutsch 1941; Tomes 1984), or as part of the story of the rise of idiot asylums in the last half of the nineteenth century (Ferguson 1992; Scheerenberger 1983; Trent 1994). However, it is useful to review the broad outlines of the debate as it initially took shape.

In the 1860 s and 1870 s, the questions being raised were mainly about what were increasingly referred to as the "chronically" or "incurably insane." At both a political and a professional level, this was a question of the centralization of state control and professional responsibility for chronic — and usually poor insane. The issue was the financial burden placed on the counties to care for these people, and also that they were being housed in terrible conditions in county poorhouses. In 1864, the New York State legislature authorized Dr. Sylvester Willard, in essence, to replicate a study done some 20 years earlier by Dorothea Dix and survey the conditions of the "insane poor" housed in the county poor houses across the state (Schneider and Deutsch 1941; Willard 1865). As did Dix, Willard found conditions that were 
largely appalling. Willard argued that the state should assume responsibility and take this growing segment of the almshouse population off the counties' hands. ${ }^{7}$ Among most institution professionals, there was little opposition to the idea that the state needed to take over the care of this population.

However, if the first question of this era- “who" should be responsible for the custody of the incurably insane-was answered fairly quickly by the expanding role of the state, the next question of "where" that responsibility should be carried out evoked a longer debate. Both within New York—and then between New York officials and professionals in other states—the question was now where to house this new population. Should existing asylums simply be expanded with the full range of patients now accepted, going from those most amenable to "cure", or the so-called acute cases, to the most chronically disturbed patients destined to a lifetime of custody with little hope for cure (Dwyer 1987)? Or, should asylums be specialized to serve a specific subset of patients so that acute and chronically ill patients would be housed in separate asylums?

All of this played out from the late 1850s to the 1880s in reference to insane asylums. However, it quickly became clear that New York's path of creating totally separate asylums for those of insane and feebleminded populations found to be beyond help would be the exception rather than the rule. The other states, with a few variations, went quickly along the route of congregate asylums with acute and chronic cases served by the same institution and residing in separate cottages rather than creating entirely separate custodial institutions. The practical implications of the so-called cottage plan were important. The move to multilevel congregate care was greatly facilitated by a move away from the linear "Kirkbride model" of asylum architecture to the "cottage" system of separate buildings arranged on a single campus with each 
building—or cottage—-housing 40-60 individuals of a specific type and functional level (Tomes 1984). Even in New York, where the specialized asylum persisted, institutions would come to follow this cottage design. It was cheaper, for one thing, to move away from the huge "bricks and columns" edifices favored by Kirkbride and the first generation of asylum superintendents, going instead to the simple, functional architecture of a basic two story box, duplicated multiple times around a central administration building. Equally important, however, the architectural move to separated buildings of simple design was inextricably bound in the policy decision to move to congregate care. In essence, the cottage system of separate buildings allowed the "best of both worlds": a congregate facility housing all levels of inmates but comprising an array of what could be characterized as separate mini-asylums in the form of cottages organized around various categories of therapeutic success and failure.

Early on in the debate, the economic utility of the cottage plan was not the primary rationale used by backers of this approach. Perhaps the most vocal opponent of the move to create a separate insane asylum for the incurably insane was John Gray, who just happened to also be the superintendent of what was at the time the only state insane asylum in New York, based in the upstate city of Utica. Although his institution had from its beginning been focused on "acute" cases—returning those who were deemed incurable to the county poorhouses—Gray argued vociferously that it would be much better to make the Utica asylum an all purpose institution, rather than create a separate custodial facility as called for by the Willard Report. In the pages of the journal he edited, The American Journal of Insanity, Gray (as summarized by Grob 1994, 108) outlined his reasons for preferring the congregate care model to the separate asylum:

1. Places like Utica couldn’t handle all of the acute cases; 
2. Chronic cases still needed treatment;

3. Separate asylums for incurables would become unwieldy;

4. $\quad$ Absence of hope created an unhealthy atmosphere;

5. Chronic patients affixed with stigma of pauperism;

6. Families would resist putting their relatives in such places (i.e., asylums for incurables). (On Separate Asylums for Curables and Incurables 1865)

Even after the New York State legislature passed the law in 1865 authorizing the creation of the Willard Custodial Asylum, Gray could only imagine that it had been the result of distracted politicians. In an unsigned article that he almost certainly authored, the misguided action is explained:

It should be borne in mind, however, that the measure was adopted by the State Government during a period of civil war, when the great question of the day absorbed every thought; and that the time and occasion were unfavorable to calm investigation and discussion of subjects of lesser moment. (On Separate Asylums 1865, 247)

Gray's position was opposed by several other institution professionals (H. B. Wilbur, George Cook, John Chapin) as well as members of the newly formed New York State Board of Charities. In the years immediately after the Willard Report was released, the response to Gray's opposition to a separate custodial insane asylum was presented in the pages of the very journal he edited. One of the main arguments was simply pointing to the failure of the Utica asylum to serve the chronic population that it now professed to want (Cook 1866).

If one were to listen to what has been said in opposition to separate provision for the chronic insane in the State of New York, having no knowledge of their actual condition, he would suppose that they were now amply provided for in curative hospitals, and that 
some restless, dissatisfied theorists, not content to leave them in such good care, were, in violation of all professional and humane ideas, endeavoring to thrust them out and precipitate them into a hell, over the gateway to which shall be inscribed, “All hope abandon, you who enter here.” (Cook 1866, 52)

Rather, Cook (1866) explained that the proposed custodial asylum would specialize in the distinct needs of the chronic insane, saving them from the degradation of the county poor houses where Gray and others apparently had been satisfied to let them remain. Facilities for the curable and incurable insane have "two distinct ends to be attained, requiring different construction, organization and management” (58). The “commingling” of the two groups would inevitably cause the institutional administration to "sacrifice the highest good of one class to the other. Need I add that the sacrifice falls mainly upon the chronic class?” (58).

Although the national debate had largely been settled by the end of the 1870s (Grob 1973) in favor of large congregate facilities, New York had taken a different path. The Willard State Asylum for the Chronic Insane was opened in 1869 (a similar facility was opened in Binghamton in 1879). By 1875 the institutional population of Willard had exceeded one thousand inmates (Grob 1973, 387). During this time, perhaps the most detailed defense of the separate custodial facility was provided by Hervey B. Wilbur. Wilbur, the superintendent at the Syracuse Idiot Asylum (later named the "Syracuse State School”) was commissioned by the New York Board of Charities to do a report on insane asylums in Great Britain, which he presented to the Board in 1876. The report was generous in its praise of institutions in Scotland, England, and the community plan used in Gheel, Belgium. In essence, Wilbur's argument for separate custodial facilities had three points: First, creating separate, single purpose asylums would allow each individual facility to stay relatively small in size, thus allowing more personalized 
supervision; second, without the burden of aggressive medical intervention in pursuit of a cure, superintendents of custodial asylums could more easily embrace the British practice of nonrestraint as advocated by Connolly and others; and finally, a focus on custody rather than cure allowed institutions to use inmates in workshop and gardening occupations that were both financially helpful to the institution and behaviorally instructive to the inmates themselves.

Not only was Wilbur generous in his praise of the British asylums that he visited. His report was also generous and specific in its criticism of Gray and the Utica asylum (Wilbur 1876). After describing at some length, the economic and therapeutic benefits to be found in the small custodial insane asylums of Scotland, where inmates were given vocational responsibilities as part of their care, Wilbur turned to Gray’s opposition to specialized custodial asylums in the United States:

It may be said, and with truth, that it is a predominance of chronic cases that permits this large percentage of employment [of able-bodied inmates] in British asylums, but this same fact is true in American asylums generally. The theory is, not that our institutions have a greater proportion of recent [i.e. potentially curable] cases and, therefore, employment is impracticable, but it is a general want of faith in employment, as a means of treatment, in any form of insanity. (Wilbur 1876, 186)

Wilbur quotes Gray's dismissal of the Scottish model for use in America and then gives his unvarnished opinion of his fellow superintendent's argument: "This is the language of one who knows nothing, by observation, of the actual facts of the case” (187).

Despite Wilbur's report and the backing of the New York State Board of Charities and Corrections, even the custodial institutions in New York would gradually yield to the national trend for congregate care of the insane. By 1890, the New York legislature had passed the "State 
Care Act." While one major feature of the act was to clearly centralize the care of the insane poor as a state responsibility, the other feature was to undo the policy of separate custodial facilities begun in 1865. Indeed, the act mandated the "abolition of the legal distinction between cases of acute and chronic mental disease” (Schneider and Deutsch 1941, 97). What had been custodial facilities in Ovid (Willard) and Binghamton, New York, became congregate care insane asylums with regional responsibility for all of the insane poor within their geographic regions.

The debate over custodial versus congregate insane asylums overshadowed the agreement that both types of facilities would be built along the cottage plan of separate buildings. The back ward, in short, was a product of the need for a separate place to house the chronically insane. From the perspective of those with the most significant disabilities, the debate over the two models of institutions was a distinction without a difference. However, from the perspective of professional control and influence, the outcome was seen as critical. Perhaps for that reason the argument would continue in New York State for several more decades. The argument shifted from asylums for the insane to those for idiots, but the issues were virtually the same as were the outcomes.

\section{Renewing the Debate: Wilbur, Kerlin, and the "Proper Care" of Custodial Idiots} As mentioned, Superintendent Gray and the backers of large, congregate asylums for the insane rather quickly carried the day in terms of institutional policy in most states. Even as Gray bemoaned the authorization of the Willard Asylum in 1865, he (anonymously but accurately) claimed that the larger debate over the arrangement of custodial care was already decided: 
There is, perhaps, no subject connected with provision for the insane, upon which the verdict of the profession has been more unanimous than their condemnation of asylums for incurables. If, as we have said, the chief source of chronic lunacy is the want of asylums for cure, it is obvious that we but palliate the evil by establishing institutions for the so-called incurable. (The Willard Asylum 1865, 207)

Wilbur did not agree with Gray's assessment and carried on the policy debate. Until his death in 1883, Wilbur pushed the notion of separate custodial asylums. However, much of his attention over those decades was focused on his primary area of professional expertise—-the idiot asylum. It was against the backdrop of the debate about custodial insane asylums that the similar but delayed debate over custodial idiot asylums played out in New York and elsewhere. ${ }^{8}$ Again, it was a debate that Wilbur was to lose, although—as we have seen—-there were advocates in New York for separate custodial idiot asylums well into the twentieth century. Taking Gray’s place in support of large congregate care facilities, housing all levels of idiots from the most educable imbecile to the most hopeless idiot, was one of Wilbur's few peers in terms of influence among idiot asylum superintendents, Isaac Kerlin of the Elwyn Asylum in Pennsylvania.

Both Wilbur and Kerlin were among the first generation of idiot asylum administrators. Unlike others of that generation(e.g., Samuel Gridley Howe and Edward Seguin), Wilbur and Kerlin were active participants in the move to establish the area of idiot asylum administration as its own medical and educational specialization, equal to but distinct from the better known field of insane asylum administration. Wilbur had actually preceded Howe and his "experimental school” for idiots—by a few months—in starting his private school in Barre, Massachusetts, in 1848 (Graney, 1979). When New York started the country's second public idiot asylum in 1852, 
Wilbur became its first superintendent. He was to remain in that position until his death more than 30 years later. For his part, Kerlin gained notice and influence as the superintendent of the prominent institution opened outside of Philadelphia—-the Pennsylvania (Elwyn) Training School—with both public and private inmates. Following Wilbur's pattern of longevity, Kerlin remained as superintendent of the facility for 30 years until his death in 1893. In 1876, both Kerlin and Wilbur were among the handful of superintendents who helped start the professional organization that would come to represent their field: the Association of Medical Officers of American Institutions for Idiots, Imbeciles and Feeble-Minded Persons.

\section{Kerlin and the "Thoroughly Classified Institution"}

In a report to his fellow superintendents in 1888, Kerlin laid out many of his reasons for preferring these larger asylums that housed all levels of idiots at one location, though separated into different cottages. In such facilities, Kerlin argued, there were economic benefits to the state, therapeutic benefits to the inmates, and what might today be called professional development opportunities for the staff.

1. Better medical care can be arranged for the "epileptic, paralytic, and scrofulous" children.

2. Under the expert eye of the superintendent, inmates may be easily moved back and forth from the "asylum branch" to the "education branch" as progress or deterioration occurs with specific individuals. Such movement would be much more difficult if the educational and custodial departments were not "in proximity.”

3. Only in congregate institutions could the "custodials" benefit from the entertainment and cultural events provided by and for the higher functioning inmates (e.g., institution bands, theatrical productions, “stereopticon” showings). 
4. The agricultural and industrial work of the physically able custodial inmates would have a "local market” in the institution itself. “[T]he gardening, laundering, and cobbling of our feeble-minded employés (sic) find here an exchange which will never be criticized by outside 'labor unions,' nor reached by 'labor legislation'” (80).

5. Just as inmates can be shifted around from one level of cottage to another, so may staff be moved from fairly unskilled work with custodial residents to more preferred (and better paid) work as matrons or teachers in the educational department.

6. Finally, and in an argument that most closely followed the concern expressed two decades earlier by John Gray, Kerlin maintained that the stigma and pessimism surrounding the hopeless care of custodial idiots would inevitably lead to what Gray referred to as an "unhealthy atmosphere" if isolated from other inmates more amenable to remediation. By contrast, when located within an 'all-purpose' facility, the custodial department is maintained as a "medical philanthropy” so that it “can never sink to the hopeless, uninviting, and deplorable condition which attaches to the common thought of an utter and complete asylum for neglected idiocy” (Kerlin 1888, 80).

Kerlin summarized his defense of the congregate facility:

In short, the experience at Elwyn attests to the economy, reasonableness, and humanity of embracing under the central administration of a general institution all the grades and classes of the idiotic and feeble-minded, living in segregate buildings, it is true, but allowed legitimate contact; each divisible from the other by a classification scientific but not rigid, yet no one group isolated from the Divine influences of hope and the human helps to improvement. (Kerlin 1888, 80-81)

At the same time that Kerlin made his case for his "all-comprehensive” institution, he made clear that the most severely disabled inmates - those who were assigned to the so-called asylum 
department—should be located at the back of such facilities, not the front. Cottages for these individuals were to be "more remote" and positioned "at some distance from the other departments—say from one-half to three-quarters of a mile” (Kerlin 1884, 260). For these facilities, big was better. Not only did size offer economies of scale, it offered a large enough population with which to demonstrate the diagnostic expertise of the asylum professionals. As mentioned earlier, taxonomic complexity—finding gradations and categories of idiocy where none had been found before-became for Kerlin and other leaders a key indication of specialized knowledge. All of that was possible only with facilities of a certain number and variety of inmate. As a result of this calculation, the very idea of small, custodial asylums was morally problematic for Kerlin:

It is the small institution against which may be pronounced the objection of moral "hospitalism.” The large, diffuse, and thoroughly classified institution is another affair, and can be to its wards and employés [sic] as cosmopolitan as a city. (Kerlin 1884, 262, emphasis added)

By the time of Kerlin's death in 1893, his plan for custodial cottages was fully implemented. The Elwyn facility had a four building “Hillside” complex matching Kerlin’s policies for type of resident and distance from the other cottages. It was purely custodial in character. One building, for example, was designated for "helpless, idiotic and epileptic boys." Another (called "the chalet”) was for “epileptic and paralytic girls” (cited in Hurd 1916, 507). Other states were gradually following the same model.

\section{Wilbur and the Developmental Divide}

For Wilbur and others in New York State, the argument for separate facilities for educable and uneducable feebleminded persons was at once more straightforward and less detailed. The 
custodial class of inmate was a diversion from the pedagogical purpose of the purely educational facility (such as the Syracuse Asylum). In language predictive of that used in 1906 by the special committee of the Board of Charities mentioned earlier, Wilbur stated clearly in his 1871 Annual Report that "The presence of these [unteachable ones] not only embarrasses the general management, but swells the average cost of taking care of the pupils generally” (Wilbur 1871, 11). Indeed, for a number of years after the opening of the Willard insane asylum in Ovid, Wilbur argued that one of the buildings at that facility should be dedicated to receive the custodial idiots gradually building up in number at Syracuse. The logic was obvious to Wilbur: "It would seem as if the mere presentation of the facts would suffice to ensure the necessary legislation” (12). By 1878, Wilbur reports to the other asylum superintendents that he and the Board of Trustees at Syracuse had always known that some alternative provision for custodial inmates would eventually have to be made. Keeping them at Syracuse was always thought, "not [to] be desirable” (Wilbur 1878, 96).

Wilbur's defense of separate facilities for custodial inmates can also be at least partly explained by his grudging insistence that his beloved institution at Syracuse was, at its heart, a school. Schools are for children. This was also a difference between idiocy and insanity, and therefore perhaps why Wilbur continued to fight for separate custodial idiot asylums even after the battle over separate insane asylums had been clearly lost. Insanity was seen largely as a disease of adults, while idiocy was almost always present from childhood. As a result, insane asylums had few children, while institutions for idiocy had many. Indeed, the earliest idiot asylums were often called "training schools" and barred admission of adults. ${ }^{9}$

The growing presence of adults represented a daily challenge to Wilbur's original conception of who he was and what he did. For him the developmental model of 
feeblemindedness was more about physical age than “mental age.” If you were an adult, you did not belong in a school, even one exclusively designed for feebleminded children. For Wilbur, there was a clear line of demarcation: if you had not moved far enough along the developmental scale to function independently or with only moderate supervision in the community, then you were custodial once you reached adulthood. This also helps explain why Wilbur argued for several years after the opening of the Willard asylum for the chronically insane, that custodial idiots could also be housed there. The point was that they were unimprovable adults; the source of their chronicity was not as important as its undeniable presence ${ }^{10}$.

Wilbur's argument about the educational function of institutions for children with milder degrees of feeblemindedness highlights one of the important differences between asylums for idiots and those for the insane. When one reads the classification schemes that were emerging for the two separate populations, it is noticeable that the focus for classifying the insane was identification of different types of insanity. With idiocy, on the other hand, the emphasis tended to be on levels of impairment. Within idiot asylums of the late 1800s, in both Europe and North America, one sees the use of increasingly elaborate levels of developmental classification (Simpson 2007). In essence what we see in these schemes is a gradual adoption of a developmental model as the basic frame within which to understand feeblemindedness in all its forms. In this frame, the feebleminded person came to be portrayed very differently than the lunatic. Unlike insanity, feeblemindedness increasingly came to be understood as a premature interruption of the individual's gradual development or maturation from child to adult. Certainly this idea really gained dominance after the turn of the century with the rapid dissemination of the Binet intelligence test and its popularization of the concept of mental age. 
As in the debate over separate, custodial insane asylums, Wilbur's position once again officially carried the day in New York State, while other states followed the advice of Kerlin and others building or enlarging large, congregate facilities with separate cottages for custodial inmates. As with the Willard Asylum, however, the official policy toward idiot asylums in New York steadily gave way to the congregate practice followed elsewhere. Kerlin even tried to rewrite Wilbur's endorsement of separate facilities as a misunderstanding that unjustly sullied his departed friend's reputation. Speaking specifically of the institution established at Newark, New York, Kerlin doubted Wilbur's support:

I think that this whole matter of Dr. Wilbur's connection with the Newark institution should not be left in doubt. We do not want to embarrass the name of that good man with any possible mistake of today. All of us who have visited it and are studying the outcome of it, agree with Mrs. Kerlin that it is a palpable mistake. My own impression is that Dr. Wilbur had no intention of permanently separating the girls from the institution at Syracuse ... The Newark institution will probably eventually become a general institution for the care and training of feeble-minded persons, irrespective of age and sex. (Kerlin 1891, 217)

Kerlin's prediction proved correct. Indeed, the defense of separate facilities was so discredited that it was thought that history should be revised so that Wilbur would not be associated with such a wrongheaded approach. ${ }^{11}$

\section{Custodialism and the Creation of the Continuum of Care}

What are we to make of this debate and its outcome? The immediate reasons for the triumph of the congregate care asylum are fairly easy to surmise. First, there were simple economies of scale to be had by building a smaller number of large facilities rather than a larger number of 
small ones. Indeed, the use of inmate labor to help run the asylums became a source of pride among superintendents. Walter Fernald of Massachusetts described the use of higher functioning female inmates to care for "the lowest grade idiots, paralytics [and] the helpless" as a way of showing the people of Massachusetts that "these trained girls can be of benefit to the state by caring for their more helpless associates” (Fernald 1891, 215). Kerlin himself bragged about maintenance costs at Elwyn decreasing from $\$ 250$ to $\$ 100$ per person because of the use of unpaid inmate labor. The male residents, for example, completely managed the institution bakery, "baking four to six barrels of flour daily at no expense for wages” (Kerlin 1891, 217).

A second reason was the administrative usefulness of having all of the clients at one setting, available to be moved and shuffled on relatively short notice. As Kerlin noted in listing his reasons for congregate care, the convenience of having the two populations-educational and custodial—in close proximity at one institution allowed such reassignments to happen more often. Of course, this also allowed the administrator a handy explanation for therapeutic failure: if a resident did not respond to intervention efforts, it was because of misclassification, not poor instruction. The failure to improve became a "success" of classification by simply moving the individual to the proper cottage following prolonged observation. Indeed, one senses that Kerlin's greatest sense of triumph came with the "thoroughly classified" institution that he was able to oversee at Elwyn. Elaborate classification of inmates became a powerful demonstration of professional legitimacy even if some of those classifications involved admission of therapeutic impotence.

Finally, it can be argued that the rapid adoption of the "cottage plan” itself was as much a cause as an effect of the move to large congregate care facilities. By moving to a model of institutional design that emphasized the use of small, separate, simple, cheaply constructed units 
(or cottages), the states could have their custodial cake and eat it too. Instead of building entirely separate custodial facilities, they were able to build the first back wards-institutions within institutions.

In the end, then, the only question that remains hard to answer is why Wilbur and his New York colleagues maintained their contrarian support for separate facilities for so long. A partial answer seems connected to Wilbur's own history. Wilbur saw himself as an educator first rather than an administrator (although he clearly acknowledged that role as well). In his closer ties to Seguin, he embodied a tradition of intervention and instruction that ran parallel to the other tradition of custody and control. His success, his claims to special expertise, were much more closely tied to educational outcomes than to administrative efficiencies. Both for Wilbur and his successors in New York, custodial inmates were more of an “embarrassment” than an opportunity.

So the issue of congregate versus separate can be seen not only as a debate over where inmates of various levels could best be served, but how professional claims to specialized knowledge could best be secured. A strategy of separate care would allow the superintendent to have the discretion of demonstrating the power of classification and assessment while focusing treatment on the salvageable minority. It gave the superintendent dominion over a smaller population but one with better prospects for valued treatment outcomes. The congregate care facility gave the superintendent control over the full range of individuals — the power to sort and serve as he saw fit on a continuing basis-where expertise is demonstrated by administrative efficiency as much as treatment efficacy (Ferguson 2002). 


\section{Conclusion}

In today's formal support system for individuals with intellectual disabilities, a continuum of placement model has come to dominate the arrangement of services (Taylor 1988). In terms of schooling, students are placed somewhere along a continuum of more or less segregated settings running from the general education classroom on one end to entirely self-contained schools on the other (Ferguson in press). For vocational services, the continuum runs from supported employment in integrated work settings to sheltered work shops to segregated "day programs" where even the pretense of vocational activity is abandoned.

Finally, we have the residential continuum. Although small, community-based apartments and homes for adults with even significant intellectual disabilities have grown in number over the last few decades, the other options of the continuum have remained persistently in place. We still have large 10-20 bed group homes that often resemble nothing so much as the industrial and farm colonies started as offshoots of institutions more than a century ago. And finally, we still have the large, public congregate institution. As mentioned earlier, almost thirty thousand individuals continue to live in such facilities, with thousands more simply shifted to private versions of the public facilities. Yet, we know from years of practice and volumes of research that these remaining "back wards"-sanitized and improved as they may be—are not required to support individuals with disabilities. Eleven states have already demonstrated that by closing their large facilities (Larson et al. 2013, 7). In every state, there are individuals with the most significant disabilities being supported in family homes or in small community alternatives. Why does the continuum of placement continue to preserve its most segregated options?

Of course, there are multiple constituencies who continue to speak on behalf of these options (including some families and some disabled individuals themselves). Moreover, the 
intentions and preferences of individuals must be interpreted in the context of structural forces that nurture and shape those personal perspectives. Although financing segregated settings has become much more costly over the last three decades — as national and state standards of staffing and support have been established and enforced — the large, congregate care facility is still often seen as the best economic alternative among the many care options now available.

The historian's answer to such a policy conundrum might return to the debate from the nineteenth century. It is the continuing professional usefulness of therapeutic failure as both a diagnostic category and a location of service that makes today’s back wards so resistant to change. The system within which professionals find themselves continues to reinforce the use of a physical location and conceptual justification for those whom professionals seem unable to help. Failure still needs a home, with or without a back ward attached.

\section{References}

Blatt, Burton. 1974. Introduction. In Christmas in Purgatory: A Photographic Essay on Mental Retardation, v-vi. Syracuse, NY: Syracuse University, Human Policy Press, Center on Human Policy.

Blatt, Burton, and Fred Kaplan. 1974. Christmas in Purgatory: A Photographic Essay on Mental Retardation. Originally published Boston, MD: Allyn \& Bacon, 1966.

Cook, George. 1866. "Provision for the Insane Poor in the State of New York.” American Journal of Insanity 23(1): 45-75.

Dwyer, Ellen. 1987. Homes for the Mad: Life Inside Two Nineteenth-Century Asylums. New Brunswick, NJ: Rutgers University Press.

Ferguson, Philip M. 2002. “Notes Toward a History of Hopelessness: Disability and the Places of Therapeutic Failure.” Disability, Culture and Education 1(1): 27-40.

- 1992. Abandoned to their Fate: Social Policy and Practice Toward Severely Retarded People in America, 1820-1920. Philadelphia: Temple University Press. 
. In press. "The Present King of France is Feeble-Minded: The Logic and History of the Continuum of Placements for People with Intellectual Disabilities.” In Righting Educational Wrongs: Disability Studies in Law and Education, edited by Arlene S. Kanter and Beth. A. Ferri. Syracuse, NY: Syracuse University Press.

Fernald, Walter. 1891. Discussion. Proceedings of the Association of Medical Officers of American Institutions for Idiotic and Feeble-Minded Persons 15: 211-218 (Transcript of discussion by Fernald and others of paper by William B. Fish.)

Graney, Bernard J. 1979. "Hervey Backus Wilbur and the Evolution of Policies and Practices Toward Mentally Retarded People.” PhD diss., Syracuse University.

Grob, Gerald N. 1994. The Mad among Us: A History of the Care of America's Mentally Ill. New York: Free Press.

—. 1973. Mental Institutions in America: Social Policy to 1875. New York: Free Press.

Hebberd, Robert W. 1912. “The Development of State Institutions for the Mentally Defective in this State for the Next Decade.” Proceedings of the New York State Conference of Charities and Correction 13: $179-190$.

Hurd, Henry. 1916. The Institutional Care of the Insane in the United States and Canada. Baltimore, MD: Johns Hopkins University Press.

Kerlin, Isaac N. 1891. "Discussion.” Proceedings of the Association of Medical Officers of American Institutions for Idiotic and Feeble-Minded Persons 15: 211-218 (Transcript of discussion by Kerlin and others of paper by William B. Fish.)

—. 1888. "Status of the Work Before the People and Legislatures." Proceedings of the Association of Medical Officers of American Institutions for Idiotic and Feeble-Minded Persons 12: 64-83.

—. 1885. "Provision for Idiots: Report of the Standing Committee.” Proceedings of the National Conference of Charities and Correction 12: 158-174.

—. 1884. "Provision for Idiotic and Feeble-Minded Children.” Proceedings of the National Conference of Charities and Correction 11: 246-263.

Larson, Sheryl, Patricia Salmi, Drew Smith, Lynda Anderson, and Amy Hewitt. 2013. Residential Services for Persons with Developmental Disabilities: Status and Trends Through 2011. Minneapolis: University of Minnesota, Research and Training Center on Community Living, Institute on Community Integration. 
Martin, M. G. 1950. “A Practical Treatment Program for a Mental Hospital “Back” Ward.” American Journal of Psychiatry 106: 758-760.

New York State Board of Charities. 1907. "Report of the Committee on Idiots and Feeble-Minded.” Annual Report 40: 171-178.

“On Separate Asylums for Curables and Incurables.” 1865. American Journal of Insanity 22: 246-252.

Rafter, Nicole H. 1997. Creating Born Criminals. Chicago, IL: University of Illinois Press.

Scheerenberger, Richard C. 1983. A History of Mental Retardation. Baltimore, MD: Paul Brookes Publishing.

Schneider, David M., and Albert Deutsch. 1941. The History of Public Welfare in New York State, 18671940. Chicago, IL: University of Chicago Press.

Shanahan, William T. 1912. "History of the Establishment and Development of the Craig Colony for Epileptics Located at Sonyea, N. Y.” Epilepsia A3(2): 153-161.

Simpson, Murray. 2007. “Developmental Concept of Idiocy.” Intellectual and Developmental Disability 45(1): 23-32.

Taylor, Steven J. 1988. "Caught in the Continuum: A Critical Analysis of the Principle of the Least Restrictive Environment.” Journal of the Association for Persons with Severe Handicaps 13(1): 45-53.

Tomes, Nancy. 1984. A Generous Confidence: Thomas Story Kirkbride and the Art of Asylum-Keeping, 1840-1883. New York: Cambridge University Press.

Trent, James W. Jr. 1994. Inventing the Feeble Mind: A History of Mental Retardation in the United States. Berkeley, CA: University of California Press.

Wilbur, Hervey B. 1878. “The Status of the Work.” Proceedings of the Association of Medical Officers of American Institutions for Idiotic and Feeble-Minded Persons 3:96-97.

—. 1876. “Management of the Insane in Great Britain.” In Annual Report, New York State Board of Charities 9: 175-207.

—. 1872. 19th Annual Report. New York State Idiot Asylum. Syracuse, NY.

—. 1871. 18th Annual Report. New York State Idiot Asylum. Syracuse, NY.

- 1858. 6th Annual Report. New York Idiot Asylum.

“The Willard Asylum and Provision for the Insane.” 1865. American Journal of Insanity 22(2): 192-212. 
Willard, Sylvester D. 1865. "Report on the Condition of the Insane Person in the County Poorhouse of New York.” Assembly Documents, New York: New York State Assembly.

${ }^{1}$ The history of the term "back ward" and its usage as a reference to places where the individuals with the most "hopeless" conditions were kept would make an interesting study of its own. At least by the 1950s, the term was appearing in the titles of academic papers, with the obvious assumption that readers would understand the reference. One of the earliest such references (Martin 1950), described the meaning of the term as follows:

Every mental hospital has one of these wards for the patients who are deteriorated but physically fit. The public thinks in terms of "The Snake Pit." The general practitioner thinks of these patients in such terms as "the hopeless and the damned." The hospital ward attendant usually feels that work with these patients lacks result, purpose, and prestige. The mental hospital doctor is usually preoccupied with his load of "new" patients, and these patients and their relatives make frequent demands upon his time and attention. (758)

${ }^{2}$ By "therapeutic failure" I mean not just the failure of individuals to show improvement while under the care of professionals but also the "official” explanation of that failure as the result of the hopelessly unsalvageable nature of the individuals' disability (Ferguson, 1992). Those individuals who "refused" to respond to the therapeutic regimen of the institution were now professionally ordained as chronic and beyond help. The problem was portrayed not as the inadequacy of the treatment but as the inadequacy of the person. For asylum administrators, the challenge presented by such individuals became the arrangement and location of their custody rather than continuing futile efforts at remediation.

${ }^{3}$ The terminology used here will often include words or phrases that are no longer used or occur only as insults. However, during the times under discussion, the terms (e.g., feebleminded, idiotic, imbecilic, insane) were part of the clinical language of the emerging class of professionals in charge of their care in institutions.

${ }^{4}$ The term "colony” in this institution's name was also meant to indicate a particular variant of the more familiar "cottage" model. The term ostensibly refers to the centuries old arrangement in Gheel, Belgium, where insane people were housed in the homes of towns people in Gheel. In the United States, a number of asylums in the nineteenth century started "farm colonies" as outposts of the main facility. These would typically be nearby the asylum, and have a resident family managing the farm and supervising 20-40 (male) inmates who were moved there. The products of their efforts were then used by the institution to defray costs. At Craig, the term "colony” was being used in a different sense, 
but still invoking at least an American perception of the Gheel arrangement. As the first Superintendent of the facility (William Shanahan) described the plan, the Colony was to differ from the cottage plan:

This colony design includes not only the separation of the patients into detached buildings, but the arrangement of the cottages upon irregular lines and at different distances, in accordance with the situations of the various building sites, adapted to the self-support of the inmates through natural advantages for economy of administration, and for the successful prosecution of trades, industries and agricultural labors. (Shanahan 1912, 155)

In practice, the facility came to resemble most of the other institutions built in this era along the cottage plan.

${ }^{5}$ As Nicole Rafter has ably described in her book Creating Born Criminals (Rafter 1997), the "unlikely alliance” (p. 41) of Wilbur and Lowell in support of the Newark asylum was a case of dramatically different perspectives about people with disabilities coalescing around a shared outcome. To oversimplify the situation, Lowell wanted to protect society from the moral depravity of feebleminded women, while Wilbur needed a place for the unimproved residents of his facility at Syracuse to move as they became adults. For both, then, the Newark asylum was a common solution to two different problems.

${ }^{6}$ At its core, the power of the concept of therapeutic failure is that it allows the professional to continue to claim success in the face of demonstrable ineffectiveness. Indeed, one way to demonstrate one's special expertise is to discover distinctions of classification where none had previously existed. So it was in this case as well: even among the custodial population, identification of the truly custodial creates a category of therapeutic failure where only generic ineffectiveness had been previously seen. The ability to diagnose permanent and inescapable failure in others was a demonstration of professional expertise.

${ }^{7}$ Interestingly, Willard's report of 1865 did find some variation in the quality of care in the poor houses around the state. Many were, indeed, apparently terrible; however, others such as the facility in Westchester County were praised as models of humane and therapeutic care. Still, despite these mixed results, Willard's strong recommendation was to build a separate state asylum and mandate the placement of chronic poor insane.

8 This lag time between developments in "treating" the insane and similar developments in "treating" idiots is remarkably persistent throughout American history. The first public insane asylum (not counting the facility at Williamsburg) was opened in Worcester, Massachusetts in 1833. That was followed 15 years later with the opening of the first “experimental school” for idiots by Samuel Gridley Howe in 1848. The first officially custodial asylum, Willard, was authorized in 1865 (though not 
actually opened until 1869). The custodial idiot asylum at Newark, New York, was opened 13 years later in 1878. In the twentieth century, the population of insane asylums peaked in 1955, before a combination of new drugs, old economics, and civil rights concerns began the move to deinstitutionalize the mentally ill. The peak population for institutions for intellectually disabled individuals came some 12 years later in 1967. If one wants to make an educated guess at what official policy toward people with intellectual disabilities will be emphasizing in 10-15 years, there would be worse approaches than simply noticing what is happening to mental health policy today.

${ }^{9}$ In his Annual Report for 1858, Wilbur extracted the relevant clause from the by-laws of the Syracuse Asylum specific as to who was — and was not—intended for admission:

Children between the ages of seven and fourteen who are idiotic, or so deficient in intelligence as to be incapable of being educated at any ordinary school, and who are not epileptic, insane or greatly deformed, may be admitted by the superintendent, with the advice and counsel of the executive counsel. (Wilbur 1858, 28, emphasis in original<AQ: Please confirm whether the said text is emphasised in this extract.>)

${ }^{10}$ In his Annual Report for 1871, Wilbur mentions the plans for the chronic insane at Ovid (the Willard Asylum) and says a similar plan should be tried with the unteachable feebleminded. Indeed, he proposed that the law authorizing the Willard Asylum be changed to allow the admission of custodial idiots as well as the chronic insane. He had investigated the issue enough to discover that there was an empty building on the land for the asylum that he proposed to use for this population. "It would seem as if the mere presentation of the facts would suffice to ensure the necessary legislation” (Wilbur 1871, 12). His presentation of the facts, however, did not suffice and he again reaffirmed his proposal in his Annual Report for the following year as well (Wilbur 1872). This time, the Board of Trustees endorsed his proposal for the Syracuse Asylum. It was all to no avail until Wilbur shifted his focus to support of the Newark Asylum as a separate custodial facility several years later.

${ }^{11}$ Wilbur's worries about the Newark facility were primarily because of its restriction to women, not because of its custodial character. 